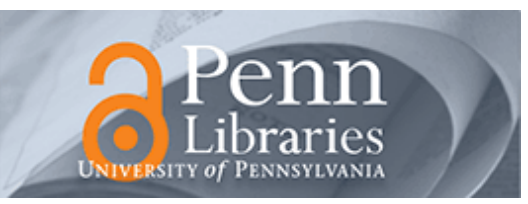

University of Pennsylvania ScholarlyCommons

$10-23-2008$

\title{
Hydrogenation of $\mathrm{Mg}$ film and $\mathrm{Mg}$ nanoblade array on Ti coated Si substrates
}

Yuping $\mathrm{He}$

University of Georgia

Yiping Zhao

University of Georgia

Liwei Huang

SUNY Binghamton

Howard Wang

SUNY Binghamton

Russell J. Composto

University of Pennsylvania, COMPOSTO@SEAS.UPENN.EDU

Follow this and additional works at: https://repository.upenn.edu/mse_papers

\section{Recommended Citation}

He, Y., Zhao, Y., Huang, L., Wang, H., \& Composto, R. J. (2008). Hydrogenation of Mg film and Mg

nanoblade array on Ti coated Si substrates. Retrieved from https://repository.upenn.edu/mse_papers/166

Hydrogenation of Mg film and Mg nanoblade array on Ti coated Si substrates Yuping He, Yiping Zhao, Liwei Huang, Howard Wang, and Russell J. Composto, Appl. Phys. Lett. 93, 163114 (2008), DOI:10.1063/1.3003880

Copyright (year) American Institute of Physics. This article may be downloaded for personal use only. Any other use requires prior permission of the author and the American Institute of Physics.

Publisher URL: http://link.aip.org/link/?APPLAB/93/163114/1

This paper is posted at ScholarlyCommons. https://repository.upenn.edu/mse_papers/166

For more information, please contact repository@pobox.upenn.edu. 


\title{
Hydrogenation of Mg film and Mg nanoblade array on Ti coated Si substrates
}

\author{
Abstract \\ The hydrogenation of $\mathrm{Mg}$ film and $\mathrm{Mg}$ nanoblade array fabricated on Ti coated Si substrates has been \\ studied and compared. The nanoblades start to absorb hydrogen at a temperature between 250 and 300 \\ degrees $\mathrm{C}$, which is much lower than 350 degrees $\mathrm{C}$ for $\mathrm{Mg}$ film. However, the saturated total hydrogen \\ uptake in nanoblades is less than half of that in the film, resulting from $\mathrm{MgO}$ formation by air exposure. \\ The nanoblade morphology with large surface area and small hydrogen diffusion length, and the catalytic \\ effect of Ti layer, are two main reasons for the nanoblade hydrogenation behavior. \\ Keywords \\ MAGNESIUM FILMS, HYDRIDE, STORAGE, DEPOSITION, SURFACES, SORPTION, NI, PD

\section{Comments} \\ Hydrogenation of $\mathrm{Mg}$ film and $\mathrm{Mg}$ nanoblade array on Ti coated Si substrates Yuping He, Yiping Zhao, \\ Liwei Huang, Howard Wang, and Russell J. Composto, Appl. Phys. Lett. 93, 163114 (2008), DOI:10.1063/ \\ 1.3003880 \\ Copyright (year) American Institute of Physics. This article may be downloaded for personal use only. Any \\ other use requires prior permission of the author and the American Institute of Physics. \\ Publisher URL: http://link.aip.org/link/?APPLAB/93/163114/1
}




\title{
Hydrogenation of $\mathrm{Mg}$ film and Mg nanoblade array on Ti coated Si substrates
}

\author{
Yuping He, ${ }^{1, a)}$ Yiping Zhao, ${ }^{1}$ Liwei Huang, ${ }^{2}$ Howard Wang, ${ }^{2}$ and Russell J. Composto ${ }^{3}$ \\ ${ }^{1}$ Department of Physics and Astronomy, and Nanoscale Science and Engineering Center, \\ University of Georgia, Athens, Georgia 30602, USA \\ ${ }^{2}$ Department of Mechanical Engineering, Binghamton University, State University of New York, \\ Binghamton, New York 13902, USA \\ ${ }^{3}$ Department of Materials Science and Engineering, University of Pennsylvania, Philadelphia, \\ Pennsylvania 19104, USA
}

(Received 7 August 2008; accepted 30 September 2008; published online 23 October 2008)

\begin{abstract}
The hydrogenation of $\mathrm{Mg}$ film and $\mathrm{Mg}$ nanoblade array fabricated on Ti coated Si substrates has been studied and compared. The nanoblades start to absorb hydrogen at a temperature between 250 and $300{ }^{\circ} \mathrm{C}$, which is much lower than $350{ }^{\circ} \mathrm{C}$ for $\mathrm{Mg}$ film. However, the saturated total hydrogen uptake in nanoblades is less than half of that in the film, resulting from $\mathrm{MgO}$ formation by air exposure. The nanoblade morphology with large surface area and small hydrogen diffusion length, and the catalytic effect of Ti layer, are two main reasons for the nanoblade hydrogenation behavior. (C) 2008 American Institute of Physics. [DOI: 10.1063/1.3003880]
\end{abstract}

Magnesium has attracted extensive research attention in the development of future solid state $\mathrm{H}$-storage materials due to its lightweight, low cost, and high reversible $\mathrm{H}$-storage capacity of 7.6 wt \% in $\mathrm{MgH}_{2}{ }^{1-3}$ However, its high thermodynamic stability and sluggish reaction kinetics limit its practical applications. ${ }^{4-6}$ Such limitations could be improved by making $\mathrm{Mg}$ nanostructures with large surface-to-volume ratios to enhance surface reactivity. Currently the Mg nanostructures are mainly fabricated via ball milling, ${ }^{2-4}$ and the resulting materials are a micrometer-sized powder with nanometer-sized grains. Mg thin film provides an ideal alternative to powder since it can be formed in a controlled environment (high vacuum). ${ }^{7-9}$ However, the grain aggregation in powder and the relatively dense characteristic of film limit the surface area increment and H-sorption activity. Recently, by using an oblique angle deposition (OAD) technique based on physical vapor deposition, both Tang et al. and $\mathrm{He}$ et al. have demonstrated that $\mathrm{Mg}$ forms nanoblade array and the structure of the nanoblades can be tailored by a geometric shadowing effect and doping. ${ }^{10,11}$ This tunable nanoblade structure provides an excellent opportunity to study the interaction of hydrogen with different intrinsic $\mathrm{Mg}$ nanostructures, and it is expected that the hydrogen sorption performance could be improved by the unique morphology of the nanoblades. In order to confirm this speculation, the hydrogenation behaviors of a dense $\mathrm{Mg}$ film and a porous $\mathrm{Mg}$ nanoblade array were studied and compared in this letter.

Both the Mg thin film and the nanoblade array were fabricated by a unique, custom designed electron-beam evaporation system (Pascal Technology) equipped with a glovebox to prevent the sample from exposing to air during the postdeposition sample transfer. The details on the experimental setup was described elsewhere. ${ }^{12}$ The chamber base pressure was $10^{-7}$ Torr. A layer of 200-nm-thick Ti film was first evaporated onto the $\mathrm{Si}$ substrates using the vapor incident angle $\alpha=10^{\circ}$ with respect to the substrate normal. This Ti layer was used as a diffusion barrier to prevent $\mathrm{Mg}$

\footnotetext{
${ }^{a)}$ Electronic mail: yphe@physast.uga.edu.
}

alloying with $\mathrm{Si}^{13}$ Then, either a $\mathrm{Mg}$ film or a Mg nanoblade array was deposited on the Ti layer by near-normal $(\alpha$ $\left.=10^{\circ}\right)$ or $\mathrm{OAD}\left(\alpha=80^{\circ}\right)$ deposition, with a $4 \mu \mathrm{m}$ thickness reading by a quartz crystal microbalance. Both the thin film (labeled as "A") and the nanoblade array (labeled as "B") samples were cut into $0.5 \times 0.5$ in. $^{2}$ pieces and were hydrogenated together in a PCT (pressure-composition isotherms) Sievert's-type apparatus (HyEnergy, PCT Pro-2000) under 20 bar H-pressure for $2000 \mathrm{~min}$ at $T=200,250,300$, and $350{ }^{\circ} \mathrm{C}$, respectively. These hydrogenated samples are labeled as "A200", "A250", "A300", and "A350" for thin film samples, and "B200", "B250", "B300", and "B350" for nanoblade samples.

The morphologies of the as-deposited and hydrogenated thin film and nanoblade samples were investigated by a fieldemission scanning electron microscopy (SEM) (FEI Inspect F), and the representative SEM images are shown in Fig. 1. As shown in the inset of Fig. 1(a), the surface of the asdeposited $\mathrm{Mg}$ film consists of piles of nanoflakes, overlapping with one another, while the cross-sectional SEM [Fig. 1(a)] reveals a typical columnar structure ${ }^{14}$ of $\mathrm{Mg}$ film with $\sim 4.0 \mu \mathrm{m}$ thickness. The as-deposited OAD sample [Fig. 1(d)] shows a well-aligned nanoblade array structure ${ }^{10,11}$ with a height of $\sim 7.1 \mu \mathrm{m}$ and a blade thickness of $\sim 160 \mathrm{~nm}$. In both Figs. 1(a) and 1(d), a thin layer of dense Ti film is also visible between the $\mathrm{Mg}$ layer and $\mathrm{Si}$ substrate. After hydrogenation at $T=300{ }^{\circ} \mathrm{C}$, almost no morphology change is observed for the $\mathrm{Mg}$ film as shown in Fig. 1(b), but the morphology of the nanoblade sample changes significantly (no change at $T \leqslant 250{ }^{\circ} \mathrm{C}$ ), and both the nanoblade height and thickness increase to $\sim 7.3 \mu \mathrm{m}$ and $220 \mathrm{~nm}$ [Fig. $1(\mathrm{e})]$, corresponding to a volume expansion of $\sim 41 \%$. When the hydrogenation temperature reaches $350{ }^{\circ} \mathrm{C}$, visible coalescence appears in the thin film [Fig. 1(c)], the flakelike surface becomes a surface with aggregated particles, and the film thickness increases to $\sim 6.2 \mu \mathrm{m}$. This corresponds to $\sim 55 \%$ volume expansion. In addition, most of the Ti thin layer still remains between $\mathrm{Mg}$ layer and substrate, and only a small quantity of $\mathrm{Mg}_{2} \mathrm{Si}$ defects are formed progressively 


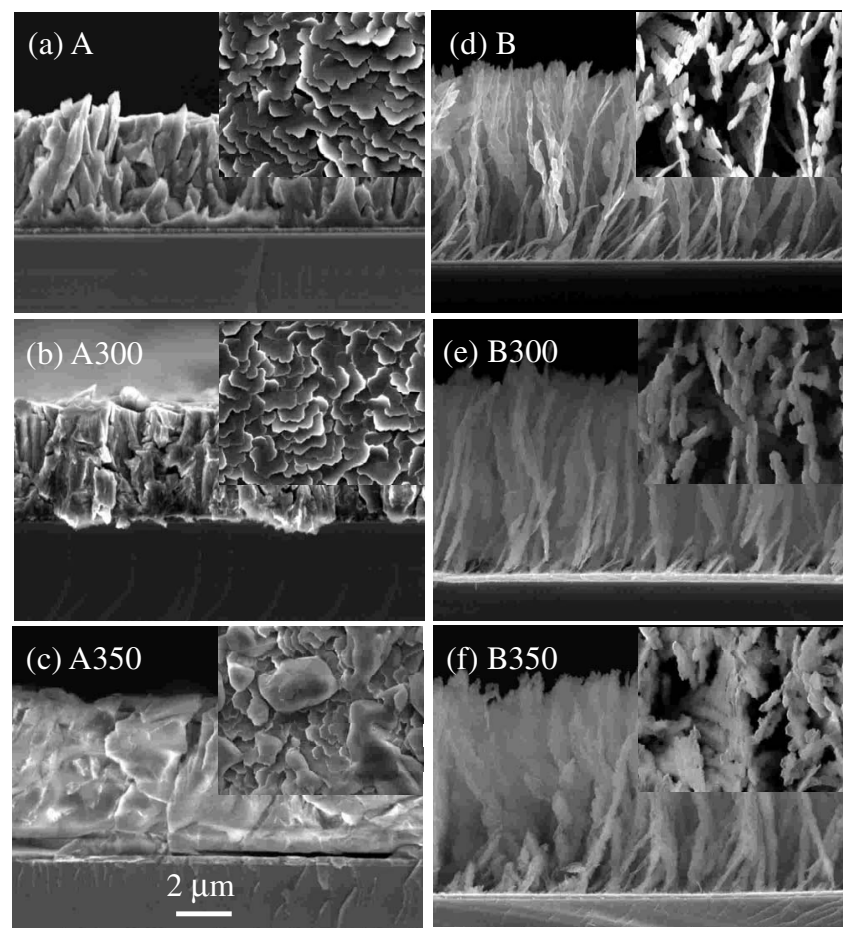

FIG. 1. Typical cross-sectional view SEM images of $\mathrm{Mg}$ films (A, A300, and A350) and nanoblades (B, B300, and B350) before and after hydrogenation at various temperatures. Their corresponding top view images are shown in the insets.

through the pinholes in the Ti film (not shown). Under the same condition, the nanoblades become longer $(\sim 7.7 \mu \mathrm{m})$ and thicker $(\sim 250 \mathrm{~nm})$ with a volume expansion of $\sim 69 \%$, and no $\mathrm{Mg}_{2} \mathrm{Si}$ defects are observed.

The changes in the chemical and crystalline structures in the hydrogenation process were investigated by the grazing angle X-ray diffraction (XRD) (PANalytical X'Pert PRO MRD). For the as-deposited film and nanoblade samples, the dominant XRD peaks are from $\mathrm{Mg}$, but the preferred crystal orientations are different, as shown in Figs. 2(a) and 2(e). For the thin film sample, even at $T=200{ }^{\circ} \mathrm{C}$, a trace amount of $\mathrm{Mg}_{2} \mathrm{Si}$ alloy starts to form [Fig. 2(b)]. This trace of $\mathrm{Mg}_{2} \mathrm{Si}$ coexists with $\mathrm{Mg}$ even at $\mathrm{T}=300{ }^{\circ} \mathrm{C}$ [Fig. 2(c)]. However, when $T$ increases to $350{ }^{\circ} \mathrm{C}$, the sample is dominated by a

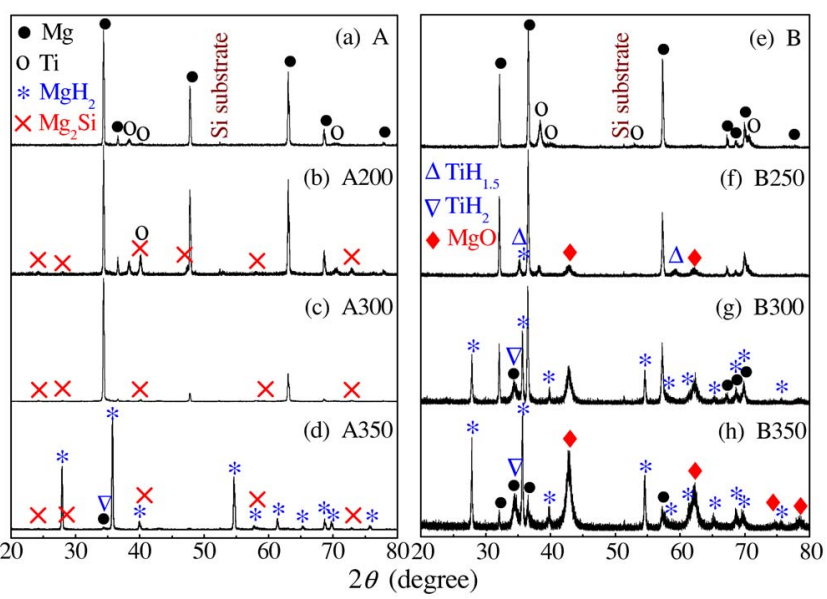

FIG. 2. (Color online) Typical XRD patterns of Mg films (A, A200, A300, and $\mathrm{A} 350)$ and nanoblades (B, B250, B300, and B350) before and after hydrogenation at various temperatures.

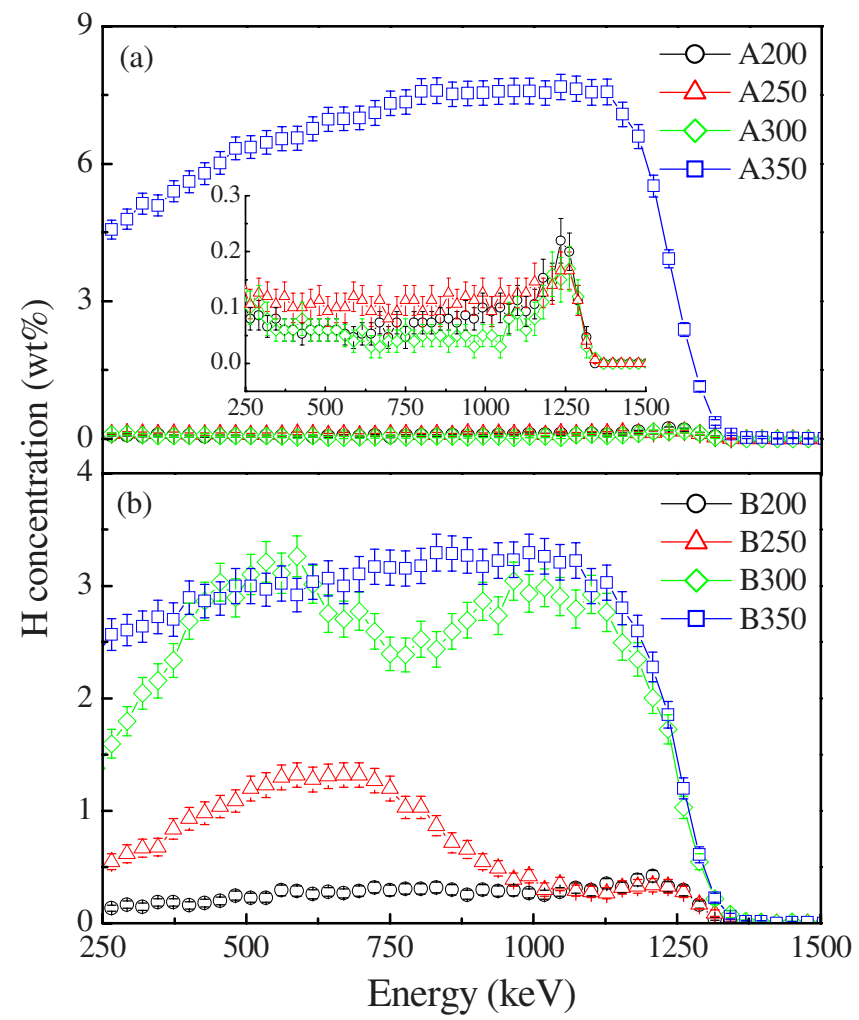

FIG. 3. (Color online) FRES spectra of (a) Mg films and (b) Mg nanoblades after hydrogenation at various temperatures. The inset in (a) shows the enlarged plots of low temperature hydrogenated films.

tetragonal $\mathrm{MgH}_{2}$ [Fig. 2(d)], although traces of $\mathrm{Mg}_{2} \mathrm{Si}, \mathrm{Mg}$, and/or $\mathrm{TiH}_{2}$ are also detectable. This significant change implies that $\mathrm{Mg}$ thin film starts to hydrogenate at near $T$ $=350{ }^{\circ} \mathrm{C}$, which is consistent with other reports. ${ }^{7,15}$ For the nanoblade sample, at $T=200{ }^{\circ} \mathrm{C}$, no detectable change is observed in the XRD pattern compared to that of the asdeposited sample. At $T=250{ }^{\circ} \mathrm{C}, \mathrm{MgO}$, cubic $\mathrm{TiH}_{1.5}$, and possible $\mathrm{MgH}_{2}$ start to form [Fig. 2(f)]. When hydrogenated at $T=300{ }^{\circ} \mathrm{C}$ [Fig. 2(g)], distinguishable but small amount of $\mathrm{MgH}_{2}$ is visible. The $\mathrm{MgO}$ peak increases significantly, and the $\mathrm{Ti}$ seems to change entirely into tetragonal $\mathrm{TiH}_{2}$. When the temperature goes up to $350{ }^{\circ} \mathrm{C}$, the $\mathrm{MgH}_{2}$ composition increases substantially, so is the $\mathrm{MgO}$. However a small amount of $\mathrm{Mg}$ still remains in the sample. Compared to the hydrogenation behavior of thin film sample, the nanoblade sample starts to hydrogenate at a lower temperature (250 or $300{ }^{\circ} \mathrm{C}$ versus $350{ }^{\circ} \mathrm{C}$ ).

To further understand the hydrogenated samples, the relative hydrogen depth profiles in both the film and nanoblade samples were measured using a forward recoil spectrometry (FRES) with a National Electrostatics Corporation (NEC) minitandem ion accelerator. ${ }^{16}$ The energy-resolved counts of $\mathrm{H}$ atoms recoiled from the sample by a $3.0 \mathrm{MeV}$ $\mathrm{He}^{2+}$ beam carry $\mathrm{H}$-depth profile information with higher and lower energy signals corresponding to the $\mathrm{H}$ concentrations near surface and deeper beneath the surface. The $\mathrm{H}$ counts were converted to $\mathrm{H}$ weight percentage by assuming that the $\mathrm{H}$ content near the film surface, namely, in the FRES energy of $800-1130 \mathrm{keV}$, of fully hydrogenated $\mathrm{Mg}$ film sample (A350) is $7.6 \mathrm{wt} \%$. Figure 3 shows the obtained FRES spectra of the $\mathrm{Mg}$ film and nanoblade samples. As shown in Fig. 3(a), for the thin film samples hydrogenated at $T \leqslant 300{ }^{\circ} \mathrm{C}$, the $\mathrm{H}$ concentration is rather minimal. The en- 


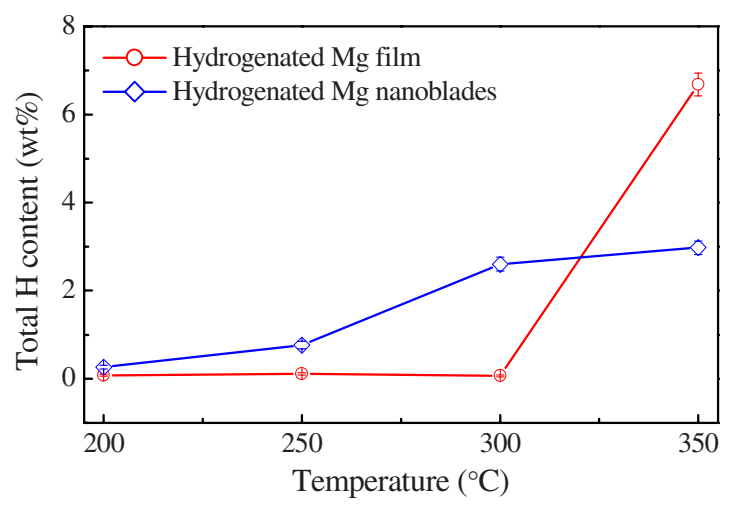

FIG. 4. (Color online) Total hydrogen uptake vs hydrogenation temperature for $\mathrm{Mg}$ films and nanoblades.

larged $\mathrm{H}$-profiles reveal a small amount of $\mathrm{H}$ enrichment at the sample surface possibly due to the water vapor adsorbed on the sample surface. ${ }^{17}$ However, at $T=350{ }^{\circ} \mathrm{C}$, a significant amount of $\mathrm{H}$ through the entire $\mathrm{Mg}$ film is detected. This agrees well with the SEM and XRD results. The $\mathrm{H}$ concentration decreases gradually from the $\mathrm{Mg}$ surface to $\mathrm{Mg} / \mathrm{Ti}$ interface, which may be caused by the formation of $\mathrm{Mg}_{2} \mathrm{Si}$ near the $\mathrm{Si}$ substrate. For the nanoblade sample, at $T$ $=200{ }^{\circ} \mathrm{C}$, a noticeable amount of $\mathrm{H}$ is present through the whole sample, as shown in Fig. 3(b). However, the XRD does not show any metal hydride formation, implying that the $\mathrm{H}$ signal in FRES may be caused by the $\mathrm{H}_{2} \mathrm{O}$ vapor absorbed in the nano-channels. ${ }^{17}$ At $T=250{ }^{\circ} \mathrm{C}$, a nonuniform $\mathrm{H}$ profile develops with significant $\mathrm{H}$ uptake occurring deep inside the nanoblades. From the XRD result, such a high $\mathrm{H}$ content could be contributed by the $\mathrm{TiH}_{1.5}$ and $\mathrm{MgH}_{2}$ near the interface between $\mathrm{Mg}$ and $\mathrm{Ti}$, and the formation of the metal hydrides could be the result of the Ti catalytic dissociating hydrogen molecules. ${ }^{18-20}$ At $T=300{ }^{\circ} \mathrm{C}$, significant $\mathrm{H}$ concentration occurs not only deep inside the nanoblades but also on the surface, which reveals that the $\mathrm{Mg}$ nanoblades themselves start to absorb $\mathrm{H}$ from the surface. When $T$ increases to $350{ }^{\circ} \mathrm{C}$, hydrogen almost distributes uniformly across the length of the nanoblades, and the shape of the $\mathrm{H}$ profile is similar to that of the thin film. However, the saturated surface $\mathrm{H}$ concentration is only $\sim 3.3 \mathrm{wt} \%$, which is much less than $7.6 \mathrm{wt} \%$ of the film sample. By integrating the $\mathrm{H}$ concentration in the energy ranging from 250 to $1250 \mathrm{keV}$, the temperature dependent hydrogen content in the thin film and nanoblade samples can be estimated and plotted in Fig. 4. It clearly shows that the activation of $\mathrm{H}$ absorption occurs between 250 and $300{ }^{\circ} \mathrm{C}$ for the nanoblade sample and between 300 and $350{ }^{\circ} \mathrm{C}$ for the thin film sample. However the saturated total $\mathrm{H}$ absorption in porous nanoblades is less than half of that in the film, and this difference may result from the formation of $\mathrm{MgO}$ in nanoblade samples.

The significant improvement of the hydrogenation thermodynamics for intrinsic $\mathrm{Mg}$ nanoblade sample may be due to the following reasons: (1) the nanoblade sample provides more surface area for $\mathrm{H}$ interacting with $\mathrm{Mg}$ and it may contain more distorted (active) Mg bonds; (2) the hydrogenation process is a volume expansion process, as demonstrated by the SEM images. Although there are nanovoids or cracks inside the thin film, in general, it only provides one direction to expand the volume; the nanoblade array, with proper separation, has almost three degrees of freedom for the volume expansion; (3) the hydrogenation process is mainly governed by the $\mathrm{H}$ diffusion and reaction. The diffusion length of $\mathrm{H}$ in nanoblades is determined by the thickness of the blades since $\mathrm{H}$ atoms have access to all around the nanoblades. For the $\mathrm{H}$ diffusion in a thin film, it is determined not only by the diffusion in $\mathrm{Mg}$ but also the thickness of $\mathrm{MgH}_{2}$ layer because this layer can slow down the $\mathrm{H}$ diffusion significantly; ${ }^{21}$ (4) since the Ti layer is buried under the $\mathrm{Mg}$ film, it only acts as a diffusion barrier during hydrogenation; for the nanoblade sample, due to the limited surface coverage of $\mathrm{Mg}$ nanoblades on Ti thin film, the Ti layer cannot only act as the diffusion barrier but also serve as a catalyst to help $\mathrm{H}_{2}$ dissociation. ${ }^{20}$ However, the porous structure of $\mathrm{Mg}$ nanoblade array makes it easy to trap $\mathrm{H}_{2} \mathrm{O}$ and $\mathrm{O}_{2}$ that could prevent a thorough hydrogenation of the sample. This disadvantage can be improved by carefully controlling the sample transfer and treatment environment.

This work was supported by a DOE Hydrogen Initiative Award (No. DE-FG02-05ER46251). The authors also would like to thank Professor Zhengwei Pan for letting us use his SEM equipment and John Gibbs for proofreading the manuscript.

${ }^{1}$ K. C. Hoffman, J. J. Reilly, F. J. Salzano, C. H. Waide, R. H. Wiswall, and W. E. Winsche, Int. J. Hydrogen Energy 1, 133 (1976).

${ }^{2}$ L. Zaluski, A. Zaluska, and J. O. StromOlsen, J. Alloys Compd. 253, 70 (1997)

${ }^{3}$ B. Sakintuna, F. Lamari-Darkrim, and M. Hirscher, Int. J. Hydrogen Energy 32, 1121 (2007).

${ }^{4}$ D. Fatay, A. Revesz, and T. Spassov, J. Alloys Compd. 399, 237 (2005).

${ }^{5}$ R. Griessen and T. Riesterer, Top. Appl. Phys. 63, 219 (1988).

${ }^{6}$ E. David, J. Mater. Process. Technol. 162, 169 (2005).

${ }^{7}$ A. Leon, E. J. Knystautas, J. Huot, and R. Schulz, J. Alloys Compd. 345, 158 (2002).

${ }^{8}$ A. Leon, E. J. Knystautas, J. Huot, S. Lo Russo, C. H. Koch, and R. Schulz, J. Alloys Compd. 356, 530 (2003).

${ }^{9}$ S. Singh, S. W. H. Eijt, M. W. Zandbergen, W. J. Legerstee, and V. L. Svetchnikov, J. Alloys Compd. 441, 344 (2007).

${ }^{10}$ F. Tang, T. Parker, H. F. Li, G. C. Wang, and T. M. Lu, J. Nanosci. Nanotechnol. 7, 3239 (2007).

${ }^{11}$ Y. P. He, Y. P. Zhao, and J. S. Wu, Appl. Phys. Lett. 92, 063107 (2008).

${ }^{12}$ Y. P. He, Z. Y. Zhang, C. Hoffmann, and Y. P. Zhao, Adv. Funct. Mater 18, 1676 (2008).

${ }^{13}$ Our recent study shows that at a moderate hydrogenation temperature, such as $200{ }^{\circ} \mathrm{C}$ or lower, $\mathrm{Mg}$ has already started to react with the $\mathrm{Si}$ substrate to form a stable $\mathrm{Mg}_{2} \mathrm{Si}$ alloy, which reduces the amount of $\mathrm{Mg}$ converted to $\mathrm{MgH}_{2}$ and strongly affects the $\mathrm{H}$-storage reversibility and cycling performance.

${ }^{14}$ R. Messier, A. P. Giri, and R. A. Roy, J. Vac. Sci. Technol. A 2, 500 (1984).

${ }^{15}$ J. L. Bobet, C. Even, Y. Nakamura, E. Akiba, and B. Darriet, J. Alloys Compd. 298, 279 (2000)

${ }^{16}$ R. J. Composto, R. M. Walters, and J. Genzer, Mater. Sci. Eng., R. 38, 107 (2002).

${ }^{17}$ The transfer of samples from Georgia to Pennsylvania for FRES measurements was under ambient condition.

${ }^{18}$ G. Liang, J. Huot, S. Boily, A. Van Neste, and R. Schulz, J. Alloys Compd. 292, 247 (1999).

${ }^{19}$ K. Nobuhara, H. Kasai, W. A. Dino, and H. Nakanishi, Surf. Sci. 566, 703 (2004).

${ }^{20}$ A. J. Du, S. C. Smith, X. D. Yao, and G. Q. Lu, J. Phys. Chem. B 109, 18037 (2005).

${ }^{21}$ P. Selvam, B. Viswanathan, C. S. Swamy, and V. Srinivasan, Int. J. Hydrogen Energy 11, 169 (1986). 